\title{
BMJ Open Lymphadenectomy and health-related quality of life after oesophageal cancer surgery: a nationwide, population-based cohort study
}

\author{
Anna Schandl, ${ }^{1}$ Asif Johar, ${ }^{1}$ Jesper Lagergren, ${ }^{2,3}$ Pernilla Lagergren ${ }^{1}$
}

\begin{abstract}
To cite: Schandl A, Johar A, Lagergren $\mathrm{J}$, et al. Lymphadenectomy and health-related quality of life after oesophageal cancer surgery: a nationwide, population-based cohort study. BMJ Open 2016;6: e012624. doi:10.1136/ bmjopen-2016-012624

- Prepublication history for this paper is available online. To view these files please visit the journal online (http://dx.doi.org/10.1136/ bmjopen-2016-012624).
\end{abstract}

Received 13 May 2016 Revised 27 June 2016 Accepted 28 July 2016

CrossMark

\begin{abstract}
${ }^{1}$ Unit of Surgical Care Science, Department of Molecular medicine and Surgery, Karolinska Institutet, Karolinska University Hospital, Stockholm, Sweden ${ }^{2}$ Unit of Upper Gastrointestinal Research, Department of Molecular medicine and Surgery, Karolinska Institutet, Karolinska University Hospital, Stockholm, Sweden ${ }^{3}$ Division of Cancer Studies, King's College London, and Guy's and St Thomas' NHS Foundation Trust, London, UK
\end{abstract}

Correspondence to Anna Schandl; anna.schandı@ki.se

\section{ABSTRACT}

Objective: The purpose of this study was to clarify whether more extensive surgical lymph node resection during oesophageal cancer surgery influences patients' health-related quality of life (HRQOL).

Setting: This was a nationwide Swedish populationbased study.

Participants: A total of 616 patients who underwent curatively intended oesophageal cancer surgery in 2001-2005 were followed up at 6 months and 5 years after surgery.

Outcome measures: HRQOL was assessed with the validated European Organisation for Research and Treatment of Cancer Quality of Life Questionnaire Core30 (EORTC QLQ-C30) and the oesophageal cancerspecific module (EORTC QLQ-OES18). The number of removed lymph nodes in relation to HRQOL was analysed using multivariable linear regression, providing mean score differences in HRQOL scores with $95 \% \mathrm{Cls}$. The results were adjusted for age, comorbidity, body mass index, tumour stage, tumour histology, postoperative complications and surgeon volume.

Results: The study included 382 and 136 patients who completed the EORTC questionnaires at 6 months and 5 years following surgery, respectively. In general, HRQOL remained stable over time, with only improvements in role function and appetite loss. A larger number of removed lymph nodes did not decrease the HRQOL measure at 6 months or 5 years after surgery.

Conclusions: More extensive lymphadenectomy during oesophageal cancer surgery might not decrease patients' short-term or long-term HRQOL, but larger studies are needed to establish this potential lack of association.

\section{INTRODUCTION}

Oesophageal cancer is the sixth most common cause of cancer-related death worldwide. ${ }^{1}$ Today, surgical resection of the oesophagus together with neoadjuvant therapy is the primary option for most patients selected for curatively intended
Strengths and limitations of this study

- It is a nationwide, population-based study with high inclusion rate of patients who have undergone curatively intended oesophageal cancer surgery.

- Limited statistical power, especially in the 5-year data, may have resulted in that moderate or weak differences between groups have remained undetected.

- The lack of baseline health-related quality of life (HRQOL) assessment has precluded adjustment for potential preoperative differences in HRQOL between groups. However, it is unlikely that any such differences would be dependent on level of lymphadenectomy.

treatment. ${ }^{2}$ The prognosis for patients diagnosed with oesophageal cancer is poor, but early tumour detection substantially increases the chance of survival. ${ }^{3}$ Oesophageal cancer often spreads through the lymphatic system, and the lymph node metastasis status is the strongest prognostic factor. To ensure oncological completeness, extensive lymphadenectomy during oesophageal cancer surgery is currently recommended. ${ }^{4}{ }^{5}$ However, recent studies indicate that extensive lymph node resection might not increase survival rate. $^{6}{ }^{7}$ A more extensive lymphadenectomy may, on the other hand, increase the surgical trauma and thus increase the risk of postoperative complications, for example, anastomotic leak, bleeding, infections, lymph leak and palsy of the laryngeal nerve. Approximately $50 \%$ of patients experience at least one postoperative complication after oesophagostomy that may require immediate intervention such as reoperation or intensive care admission. ${ }^{8}$ Surgery in itself and postoperative complications are associated with long-lasting deterioration in health-related quality of life (HRQOL),${ }^{10-14}$ and increased healthcare usage. ${ }^{15}$ To optimise the surgical 
treatment of oesophageal cancer, it is important to investigate if and how patients' HRQOL is influenced by extensive lymphadenectomy, especially if the survival rate is not improved by this factor. We aimed to test the hypothesis that more extensive surgical lymph node removal during oesophageal cancer surgery reduces patients' short-term and long-term HRQOL.

\section{METHODS}

Study design

This was a nationwide, population-based cohort study including $90 \%$ of all patients who underwent curatively intended oesophageal cancer surgery in Sweden during a 5-year period (2 April 2001-31 December 2005). Patients were followed up until the end of 2010, that is, up to 5 years following surgery. All participants gave informed consent.

\section{Data collection}

The procedure of the nationwide data collection has been described in detail elsewhere. ${ }^{8}{ }^{16}$ In short, the study was based on a complete, nationwide network of Swedish hospitals and clinicians involved in the treatment of patients with oesophageal cancer. ${ }^{17}$ Data regarding patient characteristics, tumour stage, type and location, and surgical procedure and complications were prospectively collected. The cohort also includes information about patients' self-reported HRQOL up to 5 years postoperatively.

\section{Exposure and outcome}

The study exposure was the number of removed lymph nodes during oesophageal cancer surgery. The outcome was HRQOL at 6 months and 5 years after the operation, assessed by two well-validated self-administered questionnaires developed and validated by the European Organisation for Research and Treatment of Cancer (EORTC):

1. The EORTC QLQ-C30 is a 30-item core cancer questionnaire assessing five functional dimensions of HRQOL (physical, role, cognitive, emotional and social), one global QOL scale, three symptom scales (fatigue, nausea/vomiting, pain) and six single items (appetite loss, constipation, dyspnoea, insomnia, diarrhoea and financial difficulties). The instrument is valid and reliable for HRQOL measurement in a broad range of patients with cancer. ${ }^{18}$

2. The EORTC QLQ-OES18 is an 18-item questionnaire for assessing problems specific to patients with oesophageal cancer. The questionnaire consists of four scales addressing dysphagia, eating difficulties, reflux and oesophageal pain, and six single items for choking when swallowing, coughing, speech difficulties, taste dysfunction, problems swallowing saliva and dry mouth. The questionnaire has shown good psychometric validity and is recommended when measuring HRQOL in patients with oesophageal cancer. ${ }^{19} 20$
Patients rated their perceived HRQOL and diseasespecific problems on a four-graded Likert-type scale, choosing between the following responses: 'not at all', 'a little', 'quite a bit' and 'very much'. One measure, global QOL, was rated on a seven-grade scale ranging from 1 (very poor) to 7 (excellent). The questionnaire responses were transformed into scores between 0 and 100 and missing items were handled as recommended in the EORTC scoring manual. ${ }^{21}$ In functional scales and global QOL, high scores indicate better HRQOL, whereas high scores in symptom scales and items correspond to more severe symptomatic problems. Up to three reminders were sent to the participants if no response was obtained.

\section{Statistical analysis}

The total number of lymph nodes removed was categorised into quartiles in the analysis, with the first quartile (lowest lymph node harvest) used as reference category. Mean questionnaire score differences with $95 \%$ CIs were calculated. A mean score of 10 or more was considered clinically relevant according to previous research. ${ }^{22}{ }^{23}$ We used multivariable longitudinal linear regression to analyse the association between lymphadenectomy and HRQOL. Potential confounders included in the multivariable model were as follows: (1) age (categorised as $<60,60-75$ or $>75$ years), (2) comorbidity $(0,1$ or $\geq 2$ according to the Charlson Comorbidity Index Score ${ }^{24}$ ), (3) body mass index (normal weight $<24.9$; overweight 25-29.9; or obese $\geq 30$ ), (4) tumour stage (0I, II, III or IV), (5) tumour histology (adenocarcinoma or squamous cell carcinoma), (6) postoperative complications ( 0 or $\geq 1$ complication) and (7) cumulative surgeon volume of oesophagectomies $(0-6$ or $>6$ operations per year $^{25}$ ). 'High volume' ( $>6$ operations per year) and 'low volume' (0-6 operations per year) surgeons were also analysed separately, that is, in stratified analyses. For comparison of HRQOL over time in relation to extent of lymph node removal, statistical significance was analysed when the mean score differences were $\geq 10$. $p$ Value $<0.01$ was considered as statistically significant. The statistical software SAS V.9.4 (SAS Institute, Cary, North Carolina, USA) was used for all statistical analyses.

\section{RESULTS}

Among 616 patients who underwent curatively intended oesophageal cancer surgery during the study period, 512 patients (83\%) survived the first 6 months. Among these, 382 patients $(75 \%)$ responded to the 6 -month questionnaires and were thus included in the present study. Out of these participants, 148 survived (25\%) for 5 years, of whom $136(92 \%)$ also competed the 5-year questionnaires. Characteristics of the included patients and nonresponding patients were similar, except that nonresponders were older, more often had advanced tumour stages and had more comorbidities (data not shown).

Characteristic data for included patients at 6 months are presented in table 1 , and for those at 5 years in table 2. Most patients were males, aged between 60 and 
Table 1 Characteristics of 382 patients assessed 6 months after oesophageal cancer surgery

\begin{tabular}{|c|c|c|c|c|c|c|}
\hline \multirow[b]{2}{*}{ Characteristics } & \multirow[b]{2}{*}{ Categorisation } & \multirow[b]{2}{*}{$\begin{array}{l}\text { Total cohort } \\
\text { N (\%) }\end{array}$} & \multicolumn{4}{|c|}{$\begin{array}{l}\text { Lymph nodes removed in quartiles } \\
\text { (range) }\end{array}$} \\
\hline & & & $\begin{array}{l}(0-8) \\
N(\%)\end{array}$ & $\begin{array}{l}\text { II (9-14) } \\
\text { N (\%) }\end{array}$ & $\begin{array}{l}\text { III (15-24) } \\
\text { N (\%) }\end{array}$ & $\begin{array}{l}\text { IV (24-81) } \\
\text { N (\%) }\end{array}$ \\
\hline Total & & 382 & 97 & 101 & 88 & 96 \\
\hline \multirow[t]{3}{*}{ Age } & $<60$ years & $93(24)$ & $21(22)$ & $24(24)$ & $21(24)$ & $27(28)$ \\
\hline & $60-75$ years & $240(63)$ & $65(67)$ & $61(67)$ & $56(64)$ & $58(60)$ \\
\hline & $>75$ years & 49 (13) & $11(11)$ & $16(16)$ & $11(12)$ & $11(12)$ \\
\hline \multirow[t]{2}{*}{ Sex } & Men & $311(81)$ & $76(78)$ & $82(82)$ & $76(86)$ & $77(80)$ \\
\hline & Women & 71 (19) & $21(22)$ & $19(18)$ & $12(14)$ & $19(20)$ \\
\hline \multirow[t]{3}{*}{ Comorbidity } & 0 & $116(53)$ & $59(61)$ & $55(54)$ & $44(50)$ & $56(58)$ \\
\hline & 1 & $65(30)$ & 19 (19) & $30(30)$ & $23(26)$ & $26(27)$ \\
\hline & $>1$ & $38(17)$ & $19(20)$ & $16(16)$ & $21(24)$ & $14(15)$ \\
\hline \multirow[t]{4}{*}{ Body mass index } & $<25$ & $184(48)$ & $39(40)$ & $49(48)$ & $43(49)$ & $53(55)$ \\
\hline & 25 to $<30$ & $120(31)$ & $38(40)$ & $30(30)$ & $27(31)$ & $25(26)$ \\
\hline & $\geq 30$ & $63(16)$ & $15(15)$ & $20(20)$ & $15(17)$ & $13(14)$ \\
\hline & Missing data & $15(4)$ & $5(5)$ & $2(2)$ & $3(3)$ & $5(5)$ \\
\hline \multirow{4}{*}{ Tumour stage } & 0-I & $50(23)$ & 32 (33) & 14 (14) & $13(15)$ & $20(21)$ \\
\hline & II & $64(29)$ & $25(26)$ & $37(37)$ & $29(33)$ & $24(25)$ \\
\hline & III & $88(40)$ & $35(36)$ & $45(44)$ & $36(41)$ & $40(42)$ \\
\hline & IV & $17(8)$ & $5(5)$ & $5(5)$ & $10(11)$ & $12(12)$ \\
\hline \multirow[t]{2}{*}{ Tumour histology } & Squamous cell carcinoma & $65(30)$ & $22(23)$ & $24(24)$ & $25(28)$ & $22(23)$ \\
\hline & Adenocarcinoma & $154(70)$ & $75(77)$ & $77(76)$ & $72(72)$ & $77(77)$ \\
\hline \multirow[t]{2}{*}{ Postoperative complications } & 0 & $252(66)$ & $62(64)$ & $68(67)$ & $55(63)$ & 67 (70) \\
\hline & $\geq 1$ & $130(34)$ & $35(36)$ & $33(33)$ & $33(37)$ & $29(30)$ \\
\hline \multirow[t]{2}{*}{ Surgeon volume (operations/year) } & $0-6$ & $163(43)$ & $54(56)$ & $57(57)$ & $29(33)$ & $23(24)$ \\
\hline & $>6$ & $219(57)$ & $43(44)$ & $44(43)$ & $59(67)$ & $73(76)$ \\
\hline
\end{tabular}

Table 2 Characteristics of 136 patients assessed 5 years after oesophageal cancer surgery

\begin{tabular}{|c|c|c|c|c|c|c|}
\hline \multirow[b]{2}{*}{ Characteristics } & \multirow[b]{2}{*}{ Categorisation } & \multirow[b]{2}{*}{$\begin{array}{l}\text { Total cohort } \\
\mathrm{N}(\%)\end{array}$} & \multicolumn{4}{|c|}{$\begin{array}{l}\text { Lymph nodes removed in quartiles } \\
\text { (range) }\end{array}$} \\
\hline & & & $\begin{array}{l}(0-8) \\
N(\%)\end{array}$ & $\begin{array}{l}\text { II (9-14) } \\
\mathrm{N}(\%)\end{array}$ & $\begin{array}{l}\text { III (15-24) } \\
\text { N (\%) }\end{array}$ & $\begin{array}{l}\text { IV (24-81) } \\
\text { N (\%) }\end{array}$ \\
\hline Total & & 136 & 33 & 30 & 33 & 40 \\
\hline \multirow[t]{3}{*}{ Age } & $<60$ years & $36(26)$ & $8(24)$ & $7(23)$ & $11(33)$ & $10(25)$ \\
\hline & $60-75$ years & $92(68)$ & $23(70)$ & $18(60)$ & $21(64)$ & $30(75)$ \\
\hline & $>75$ years & $8(6)$ & $2(6)$ & $5(17)$ & $1(3)$ & $0(0)$ \\
\hline \multirow[t]{2}{*}{ Sex } & Men & $108(79)$ & 27 (82) & $24(80)$ & 27 (82) & $30(75)$ \\
\hline & Women & $28(21)$ & $6(18)$ & $6(20)$ & $6(18)$ & $10(25)$ \\
\hline \multirow[t]{3}{*}{ Comorbidity } & 0 & $75(55)$ & $20(61)$ & $14(47)$ & $21(64)$ & $20(50)$ \\
\hline & 1 & $38(28)$ & $5(15)$ & $11(37)$ & $8(24)$ & $14(35)$ \\
\hline & $>1$ & $23(17)$ & $8(24)$ & $5(16)$ & $4(12)$ & $6(15)$ \\
\hline \multirow[t]{4}{*}{ Body mass index } & $<25$ & $62(46)$ & $12(36)$ & $13(43)$ & $15(46)$ & $22(55)$ \\
\hline & 25 to $<30$ & 46 (34) & $14(43)$ & $8(27)$ & $12(36)$ & $12(30)$ \\
\hline & $\geq 30$ & $27(20)$ & $7(21)$ & $8(27)$ & $6(18)$ & $6(15)$ \\
\hline & Missing data & $1(1)$ & $0(0)$ & 1 (3) & $0(0)$ & $0(0)$ \\
\hline \multirow{4}{*}{ Tumour stage } & $0-1$ & $64(47)$ & $24(73)$ & $13(43)$ & $9(27)$ & $18(45)$ \\
\hline & ॥ & $41(30)$ & $7(21)$ & $9(30)$ & $15(46)$ & $10(25)$ \\
\hline & III & $27(20)$ & $2(6)$ & $8(27)$ & $8(24)$ & $9(23)$ \\
\hline & IV & 4 (3) & $0(0)$ & $0(0)$ & 1 (3) & $3(7)$ \\
\hline \multirow{2}{*}{ Tumour histology } & Squamous cell carcinoma & $34(25)$ & $6(18)$ & 7 (23) & $11(33)$ & $10(25)$ \\
\hline & Adenocarcinoma & $102(75)$ & 27 (82) & $23(77)$ & $22(67)$ & $30(75)$ \\
\hline \multirow[t]{2}{*}{ Postoperative complications } & 0 & 87 (64) & $21(64)$ & $21(70)$ & $20(61)$ & $25(62)$ \\
\hline & $\geq 1$ & $49(36)$ & $12(36)$ & $9(30)$ & $13(39)$ & $15(38)$ \\
\hline \multirow[t]{2}{*}{ Surgeon volume (operations/year) } & $\overline{0}-6$ & $55(40)$ & $16(48)$ & $19(63)$ & $11(33)$ & $9(23)$ \\
\hline & $>6$ & $81(60)$ & $17(52)$ & $11(37)$ & $22(67)$ & $31(77)$ \\
\hline
\end{tabular}


75 years and without comorbidities. The median number of removed lymph nodes was 14 (range 0-81). Patient characteristics in the four lymphadenectomy quartile groups were similar, except for more advanced tumour stages and higher surgeon volume in lymphadenectomy quartiles III and IV. Median length of survival was similarly distributed in the four quartiles.

Extent of lymph nodes removal and short-term HRQOL

There was no influence of more extensive surgical lymph node removal on HRQOL at 6-month follow-up (table 3). Global QOL, functions, and general and oesophageal symptoms were similar between the lymphadenectomy quartiles, with no clinically significant differences in mean questionnaire scores. Data were also stratified by two categories of surgeon volume, but the results were similar in both categories (data not shown).

Extent of lymph node removal and long-term HRQOL Long-term HRQOL showed no deterioration in patients with more extensive lymph node resection (table 4). Results remained similar when data were stratified by surgeon volume (data not shown). Global QOL, function and symptom scales did not reveal any worse mean score

Table 3 Number of lymph nodes removed (quartiles I-IV) in relation to health-related quality of life aspects in 382 patients 6 months after oesophageal cancer surgery

\begin{tabular}{|c|c|c|c|c|}
\hline \multirow[b]{2}{*}{$\begin{array}{l}\text { Questionnaire scales } \\
\text { and items }\end{array}$} & \multirow{2}{*}{$\begin{array}{l}\text { Adjusted* } \\
\text { questionnaire } \\
\text { scores } \\
\text { I (0-8 nodes) } \\
\text { Reference }\end{array}$} & \multicolumn{3}{|c|}{ Mean score differences (95\% Cls) } \\
\hline & & $\begin{array}{l}\text { II (9-14 } \\
\text { nodes) }\end{array}$ & $\begin{array}{l}\text { III (15-24 } \\
\text { nodes) }\end{array}$ & $\begin{array}{l}\text { IV (24-81 } \\
\text { nodes) }\end{array}$ \\
\hline \multicolumn{5}{|l|}{ EORTC QLQ-C30 } \\
\hline Global quality of life & 50 (45 to 56$)$ & $3(-3$ to 10$)$ & $1(-5$ to 8$)$ & $6(0$ to 13$)$ \\
\hline \multicolumn{5}{|l|}{ Functional scales } \\
\hline Physical & 68 (62 to 73$)$ & $1(-5$ to 6$)$ & $0(-6$ to 6$)$ & $3(-3$ to 9$)$ \\
\hline Role & 53 (45 to 61$)$ & $5(-4$ to 14$)$ & $0(-9$ to 10$)$ & $4(-5$ to 13$)$ \\
\hline Cognitive & 75 (70 to 80$)$ & $6(0$ to 12$)$ & $1(-6$ to 7$)$ & $1(-5$ to 8$)$ \\
\hline Emotional & 63 (58 to 69$)$ & 9 (2 to 15$)$ & $4(-2$ to 11$)$ & $4(-3$ to 10$)$ \\
\hline Social & 63 (56 to 70$)$ & 8 (1 to 16$)$ & $2(-6$ to 10$)$ & $5(-2$ to 13$)$ \\
\hline \multicolumn{5}{|l|}{ Symptom scales } \\
\hline Fatigue & 53 (46 to 60$)$ & $-3(-11$ to 4$)$ & $-2(-10$ to 6$)$ & $-4(-11$ to 4$)$ \\
\hline Nausea/vomiting & 26 (20 to 31$)$ & $-6(-12$ to 0$)$ & $-6(-13$ to 0$)$ & $-8(-15$ to -2$)$ \\
\hline Pain & 36 (29 to 43$)$ & $-7(-14$ to 1$)$ & $3(-5$ to 11$)$ & $1(-7$ to 9$)$ \\
\hline \multicolumn{5}{|l|}{ Symptom items } \\
\hline Appetite loss & 47 (39 to 55$)$ & $1(-8$ to 11$)$ & $-2(-12$ to 7$)$ & $-5(-15$ to 4$)$ \\
\hline Constipation & 19 (14 to 25$)$ & $-2(-9$ to 4$)$ & $-8(-14$ to -1$)$ & $-3(-10$ to 3$)$ \\
\hline Dyspnoea & 42 (35 to 50$)$ & $0(-8$ to 9$)$ & $3(-6$ to 11$)$ & $0(-9$ to 8$)$ \\
\hline Insomnia & 31 (23 to 38$)$ & $-3(-12$ to 5$)$ & $-2(-11$ to 7$)$ & 1 (-8 to 9$)$ \\
\hline Diarrhoea & 33 (25 to 41$)$ & $-5(-13$ to 4$)$ & $-3(-12$ to 6$)$ & $-9(-18$ to 0$)$ \\
\hline Financial difficulties & 19 (13 to 26$)$ & $2(-5$ to 9$)$ & $3(-4$ to 11$)$ & $1(-6$ to 8$)$ \\
\hline \multicolumn{5}{|l|}{ EORTC QLQ-OES18 } \\
\hline \multicolumn{5}{|c|}{ Disease-specific symptom scales } \\
\hline Dysphagia & 31 (24 to 38$)$ & $1(-7$ to 8$)$ & $-2(-10$ to 6$)$ & $-6(-14$ to 2$)$ \\
\hline Eating difficulties & 41 (35 to 47$)$ & $-1(-8$ to 6$)$ & $0(-7$ to 8$)$ & $-4(-11$ to 3$)$ \\
\hline Reflux & 25 (18 to 32$)$ & $-2(-11$ to 6$)$ & $-3(-12$ to 6$)$ & $-2(-10$ to 6$)$ \\
\hline Oesophageal pain & 31 (25 to 37 ) & $-9(-15$ to -2$)$ & $-1(-8$ to 6$)$ & $-5(-12$ to 2$)$ \\
\hline \multicolumn{5}{|l|}{ Disease-specific items } \\
\hline Choking & 22 (16 to 29$)$ & $0(-7$ to 7$)$ & $6(-1$ to 13$)$ & $-2(-10$ to 5$)$ \\
\hline Coughing & 28 (21 to 36$)$ & $2(-7$ to 10$)$ & $-4(-13$ to 5$)$ & $0(-9$ to 9$)$ \\
\hline Speech difficulties & 18 (12 to 23$)$ & $0(-7$ to 6$)$ & $1(-5$ to 8$)$ & $-2(-9$ to 4$)$ \\
\hline Taste problems & 30 (23 to 37$)$ & $-7(-15$ to 1$)$ & $-1(-9$ to 8$)$ & $-4(-12$ to 5$)$ \\
\hline Trouble swallowing saliva & 14 (8 to 21$)$ & 5 (-3 to 12$)$ & $1(-7$ to 8$)$ & $3(-5$ to 10$)$ \\
\hline Dry mouth & 27 (20 to 35$)$ & $4(-4$ to 13$)$ & $2(-7$ to 11$)$ & $1(-8$ to 9$)$ \\
\hline $\begin{array}{l}\text { *Adjusted for age, comorbidity, } \\
\text { volume. } \\
\text { EORTC QLQ-C30, European O } \\
\text { QLQ-OES18, European Organi } \\
\text { module. }\end{array}$ & $\begin{array}{l}\text { s index, tumour } \\
\text { on for Research } \\
\text { Research and } T\end{array}$ & $\begin{array}{l}\text { nour histology, } \\
\text { ment of Cancer } \\
\text { of Cancer Quali }\end{array}$ & $\begin{array}{l}\text { ve complications } \\
\text { ife Questionnai } \\
\text { uestionnaire oes }\end{array}$ & $\begin{array}{l}\text { lative surgeon } \\
\text { EORTC } \\
\text { sancer-specific }\end{array}$ \\
\hline
\end{tabular}


Table 4 Number of lymph nodes removed (quartiles I-IV) in relation to health-related quality of life aspects in 136 patients 5 years after oesophageal cancer surgery

\begin{tabular}{|c|c|c|c|c|}
\hline \multirow[b]{2}{*}{$\begin{array}{l}\text { Questionnaire scales } \\
\text { and items }\end{array}$} & \multirow{2}{*}{$\begin{array}{l}\text { Adjusted* } \\
\text { questionnaire } \\
\text { scores } \\
\text { I (0-8 nodes) } \\
\text { Reference }\end{array}$} & \multicolumn{3}{|c|}{ Mean score differences (95\% Cls) } \\
\hline & & II (9-14 nodes) & $\begin{array}{l}\text { III (15-24 } \\
\text { nodes) }\end{array}$ & $\begin{array}{l}\text { IV (24-81 } \\
\text { nodes) }\end{array}$ \\
\hline \multicolumn{5}{|l|}{ EORTC QLQ-C30 } \\
\hline Global quality of life & 59 (50 to 67$)$ & $5(-6$ to 16$)$ & $4(-7$ to 14$)$ & $0(-11$ to 10$)$ \\
\hline \multicolumn{5}{|l|}{ Functional scales } \\
\hline Physical & 74 (66 to 82$)$ & $-5(-15$ to 5$)$ & $-3(-13$ to 7$)$ & $1(-8$ to 11$)$ \\
\hline Role & 64 (52 to 77$)$ & $4(-12$ to 20$)$ & 6 (-9 to 22$)$ & $9(-6$ to 24$)$ \\
\hline Cognitive & 74 (65 to 82$)$ & $5(-6$ to 15$)$ & $-2(-13$ to 8$)$ & $5(-5$ to 15$)$ \\
\hline Emotional & 68 (59 to 77$)$ & $9(-2$ to 21$)$ & $6(-5$ to 17$)$ & $6(-4$ to 17$)$ \\
\hline Social & 74 (64 to 85$)$ & $3(-11$ to 16$)$ & $3(-10$ to 16$)$ & $2(-10$ to 14$)$ \\
\hline \multicolumn{5}{|l|}{ Symptom scales } \\
\hline Fatigue & 46 (35 to 56$)$ & $-9(-23$ to 4$)$ & $1(-12$ to 14$)$ & $-3(-15$ to 10$)$ \\
\hline Nausea/vomiting & 15 (6 to 23$)$ & $-1(-12$ to 10$)$ & $2(-9$ to 13$)$ & $-1(-11$ to 9$)$ \\
\hline Pain & 23 (12 to 33$)$ & $1(-12$ to 15$)$ & $7(-6$ to 20$)$ & $11(-2$ to 23$)$ \\
\hline \multicolumn{5}{|l|}{ Symptom items } \\
\hline Appetite loss & 41 (28 to 54$)$ & $-10(-26$ to 6$)$ & $-8(-24$ to 8$)$ & $-16(-31$ to -1$)$ \\
\hline Constipation & $11(2$ to 19$)$ & $4(-7$ to 14$)$ & $4(-7$ to 15$)$ & $3(-7$ to 14$)$ \\
\hline Dyspnoea & 39 (27 to 50$)$ & $-3(-18$ to 12$)$ & $2(-12$ to 17$)$ & $0(-14$ to 14$)$ \\
\hline Insomnia & 36 (24 to 47$)$ & $-8(-24$ to 7$)$ & $-10(-24$ to 5$)$ & $0(-15$ to 14$)$ \\
\hline Diarrhoea & 33 (21 to 45$)$ & $-12(-27$ to 4$)$ & $-13(-28$ to 2$)$ & $-16(-30$ to -2$)$ \\
\hline Financial difficulties & 17 (7 to 26$)$ & $-3(-15$ to 10$)$ & $0(-12$ to 12$)$ & $0(-12$ to 11$)$ \\
\hline \multicolumn{5}{|l|}{ EORTC QLQ-OES18 } \\
\hline \multicolumn{5}{|c|}{ Disease-specific symptom scales } \\
\hline Dysphagia & 29 (19 to 40$)$ & $-4(-18$ to 9$)$ & $-4(-17$ to 10$)$ & $-7(-19$ to 6$)$ \\
\hline Eating difficulties & 40 (30 to 50$)$ & $-12(-25$ to 1$)$ & $-10(-22$ to 2$)$ & $-13(-25$ to -2$)$ \\
\hline Reflux & 29 (18 to 40$)$ & $0(-14$ to 15$)$ & $3(-11$ to 17$)$ & $7(-6$ to 21$)$ \\
\hline Oesophageal pain & 23 (14 to 32$)$ & $3(-9$ to 14$)$ & $-1(-12$ to 11$)$ & $0(-11$ to 10$)$ \\
\hline \multicolumn{5}{|l|}{ Disease-specific items } \\
\hline Choking & 19 (9 to 29$)$ & $-3(-16$ to 9$)$ & $3(-10$ to 15$)$ & $-2(-13$ to 10$)$ \\
\hline Coughing & 16 (4 to 27$)$ & $4(-11$ to 19$)$ & $8(-6$ to 23$)$ & $5(-9$ to 20$)$ \\
\hline Speech difficulties & 15 (6 to 24$)$ & $-4(-15$ to 7$)$ & $0(-11$ to 11$)$ & $-5(-15$ to 6$)$ \\
\hline Taste problems & 27 (15 to 38$)$ & $-13(-28$ to 1$)$ & $-7(-21$ to 7$)$ & $-6(-20$ to 7$)$ \\
\hline Trouble swallowing saliva & $9(-1$ to 19$)$ & 13 (0 to 25$)$ & $12(0$ to 24$)$ & $3(-9$ to 15$)$ \\
\hline Dry mouth & 23 (11 to 35$)$ & $2(-13$ to 17$)$ & $9(-6$ to 24$)$ & $-3(-17$ to 11$)$ \\
\hline
\end{tabular}

differences with more extensive lymphadenectomy. Patients with the highest number of resected nodes (quartile IV) had rather less severe symptoms of appetite loss (mean score difference: $-16,95 \%$ CI -31 to -1 ), diarrhoea (mean score difference: $-16,95 \%$ CI -30 to -2 ) and eating difficulties (mean score difference: $-13,95 \%$ CI -25 to -2 ) compared with the reference group (quartile I). Trouble swallowing saliva was more often found to be a problem in patients in lymphadenectomy quartile II (mean score difference: $13,95 \%$ CI 0 to 25 ) and III (mean score difference: $12,95 \%$ CI 0 to 24 ). Three-year follow-up data were also analysed, but these were similar to the 5-year data and are therefore not presented.
Extent of lymph node removal and HRQOL changes between 6 months and 5 years

Most HRQOL aspects were similar between patients in the four categories of lymph node yield when analysing HRQOL changes between 6 months and 5 years of surgery (table 5). A clinically relevant and statistically significant improvement was seen in role function for patients in quartile III (mean score difference: 17, 95\% CI 5 to 30) and quartile IV (mean score difference: 16, 95\% CI 4 to 28). Appetite loss was clinically and statistically significantly reduced during the time period for patients in quartile IV (mean score difference: $-16,95 \%$ CI -28 to -4$)$. 
Table 5 Changes in health-related quality of life in relation to number of lymph nodes removed (quartiles I-IV) for 136 patients with data at 6 months and 5 years after oesophageal cancer surgery, presented as mean score differences (MSDs), $95 \%$ Cls and $\mathrm{p}$ values

\begin{tabular}{|c|c|c|c|c|c|c|c|c|}
\hline \multirow{3}{*}{$\begin{array}{l}\text { Questionnaire scales } \\
\text { and items }\end{array}$} & \multicolumn{8}{|c|}{ Health-related quality of life changes between 6 months and 5 years } \\
\hline & \multicolumn{2}{|l|}{ I (0-8 nodes) } & \multicolumn{2}{|l|}{ II (9-14 nodes) } & \multicolumn{2}{|l|}{ III (15-24 nodes) } & \multicolumn{2}{|l|}{ IV (24-81 nodes) } \\
\hline & MSD (95\% Cl) & p Value* & MSD (95\% Cl) & p Value* & MSD (95\% Cl) & p Value* & MSD (95\% Cl) & p Value* \\
\hline \multicolumn{9}{|l|}{ EORTC QLQ-C30 } \\
\hline Global quality of life & $8(-1$ to 17$)$ & - & $9(0$ to 19$)$ & - & $11(2$ to 20$)$ & 0.02 & $2(-7$ to 10$)$ & - \\
\hline \multicolumn{9}{|l|}{ Functional scales } \\
\hline Physical & $7(-2$ to 15$)$ & - & $1(-7$ to 9$)$ & - & $4(-4$ to 12$)$ & - & 5 (-3 to 12$)$ & - \\
\hline Role & $11(-1$ to 24$)$ & 0.08 & $10(-3$ to 24$)$ & 0.12 & $17(5$ to 30$)$ & 0.008 & 16 (4 to 28$)$ & 0.008 \\
\hline Cognitive & $-1(-10$ to 7$)$ & - & $-3(-12$ to 6$)$ & - & $-4(-13$ to 5$)$ & - & $2(-6$ to 10$)$ & - \\
\hline Emotional & $5(-4$ to 14$)$ & - & $6(-4$ to 15$)$ & - & $7(-2$ to 16$)$ & - & $8(0$ to 16$)$ & - \\
\hline Social & 11 (1 to 22$)$ & 0.04 & $5(-6$ to 16$)$ & - & $12(2$ to 23$)$ & 0.02 & $8(-2$ to 18$)$ & - \\
\hline \multicolumn{9}{|l|}{ Symptom scales } \\
\hline Fatigue & 8 (-18 to 3$)$ & - & $-13(-24$ to -2$)$ & 0.02 & $-4(-15$ to 6$)$ & - & $-7(-17$ to 3$)$ & - \\
\hline Nausea/vomiting & $-11(-20$ to -2$)$ & 0.01 & $-5(-14$ to 4$)$ & - & $-3(-12$ to 6$)$ & - & $-4(-12$ to 5$)$ & - \\
\hline Pain & $-13(-24$ to -2$)$ & 0.02 & $-5(-16$ to 6$)$ & - & $-9(-20$ to 2$)$ & - & $-3(-13$ to 7$)$ & - \\
\hline \multicolumn{9}{|l|}{ Symptom items } \\
\hline Appetite loss & $-6(-19$ to 7$)$ & - & $-17(-31$ to -4$)$ & 0.01 & $-11(-24$ to 2$)$ & 0.08 & $-16(-28$ to -4$)$ & 0.009 \\
\hline Constipation & $-9(-18$ to 0$)$ & - & $-3(-12$ to 6$)$ & - & $3(-6$ to 12$)$ & - & $-2(-10$ to 6$)$ & - \\
\hline Dyspnoea & $-3(-15$ to 9$)$ & - & $-7(-19$ to 6$)$ & - & $-4(-16$ to 8$)$ & - & $-3(-14$ to 8$)$ & - \\
\hline Insomnia & 5 (-7 to 17$)$ & - & $0(-13$ to 12$)$ & - & $-3(-15$ to 9$)$ & - & $4(-7$ to 15$)$ & - \\
\hline Diarrhoea & $-1(-13$ to 12$)$ & - & $-7(-20$ to 5$)$ & - & $-10(-23$ to 2$)$ & 0.10 & $-8(-19$ to 4$)$ & - \\
\hline Financial difficulties & $-3(-13$ to 7$)$ & - & $-8(-18$ to 3$)$ & - & $-6(-16$ to 4$)$ & - & $-4(-13$ to 5$)$ & - \\
\hline \multicolumn{9}{|l|}{ EORTC QLQ-OES 18} \\
\hline \multicolumn{9}{|c|}{ Disease-specific symptom scales } \\
\hline Dysphagia & $-2(-13$ to 9$)$ & - & $-7(-18$ to 4$)$ & - & $-3(-14$ to 8$)$ & - & $-3(-13$ to 8$)$ & - \\
\hline Eating difficulties & $-1(-11$ to 9$)$ & - & $-12(-22$ to -1$)$ & 0.03 & $-11(-21$ to -1$)$ & 0.03 & $-10(-20$ to -1$)$ & 0.03 \\
\hline Reflux & $4(-8$ to 15$)$ & - & $6(-5$ to 18$)$ & - & $10(-2$ to 22$)$ & 0.10 & $13(2$ to 24$)$ & 0.02 \\
\hline Oesophageal pain & $-9(-18$ to 1$)$ & - & $3(-7$ to 12$)$ & - & $-8(-18$ to 1$)$ & - & $-4(-13$ to 5$)$ & - \\
\hline \multicolumn{9}{|l|}{ Disease-specific items } \\
\hline Choking & $-4(-14$ to 6$)$ & - & $-7(-17$ to 4$)$ & - & $-7(-17$ to 3$)$ & - & $-3(-12$ to 6$)$ & - \\
\hline Coughing & $-13(-25$ to 0$)$ & 0.04 & $-10(-22$ to 3$)$ & 0.12 & $0(-13$ to 12$)$ & - & $-7(-18$ to 4$)$ & - \\
\hline Speech difficulties & $-3(-12$ to 6$)$ & - & $-7(-16$ to 3$)$ & - & $-5(-14$ to 4$)$ & - & $-5(-14$ to 3$)$ & - \\
\hline Taste problems & $-3(-15$ to 9$)$ & - & $-10(-22$ to 2$)$ & 0.12 & $-10(-21$ to 2$)$ & 0.11 & $-6(-17$ to 5$)$ & - \\
\hline Trouble swallowing saliva & $-6(-16$ to 5$)$ & - & $2(-8$ to 13$)$ & - & $6(-4$ to 16$)$ & - & $-6(-15$ to 4$)$ & - \\
\hline Dry mouth & $-4(-17$ to 8$)$ & - & $-7(-19$ to 6$)$ & - & $3(-10$ to 15$)$ & - & $-8(-19$ to 3$)$ & - \\
\hline
\end{tabular}

$-4(-17$ to 8$)$

$-7(-19$ to 6$)$

$3(-10$ to 15$)$

p Values $<0.01$ were considered statistically significant.

*Where mean scores differed clinically relevantly by $\geq 10$ points, linear regression was used to test for statistical significance.

EORTC QLQ-C30, European Organisation for Research and Treatment of Cancer Quality of Life Questionnaire Core-30; EORTC QLQ-OES18, European Organisation for Research and Treatment of Cancer Quality of Life Questionnaire oesophageal cancer-specific module. 


\section{DISCUSSION}

In this study, more extensive lymph node removal during oesophageal cancer surgery did not decrease patients' short-term or long-term HRQOL. Irrespective of the extent of lymphadenectomy, few clinical improvements in HRQOL over time were seen.

However, results should be interpreted in the light of study strengths and limitations. A nationwide populationbased design with high inclusion rate of patients who underwent curatively intended oesophageal cancer surgery reduces the risk of selection bias. Yet, even though follow-up rate at 6 months and 5 years was high (75\% and $92 \%$, respectively), we cannot preclude that non-participation influenced the results, since responders tended to be healthier. However, it is unlikely that non-participation was associated with the extent of lymphadenectomy, and thus selection bias should not be a major concern. The number of identified lymph nodes is a result of the lymphadenectomy per se, but the pathologists also play an important role in identifying lymph nodes. Therefore, some level of exposure misclassification is expected. Such bias is likely at random, but may lead to dilution of potential associations. However, the number of detected lymph nodes in this population-based study of all hospitals in Sweden remains a valid marker of the extent of lymphadenectomy. The use of well-validated questionnaires reduced the risk of information bias. Results were adjusted for all established prognostic factors, which counteracts confounding. However, residual confounding cannot be eliminated, for example, by surgeon volume. More experienced surgeons tend to remove more lymph nodes and they have better postoperative outcomes regarding complications and mortality. ${ }^{26}$ However, stratification by surgeon volume did not change the results. The results were adjusted for several potential confounding factors, but we did not adjust for surgical technique. The reason for this is that the dominating surgical procedure in Sweden during the entire study period was the 'Ivor-Lewis technique'. Therefore, we do not believe that surgical technique was a confounder in the present study. The lack of baseline HRQOL assessment is a limitation that precludes adjustment for potential preoperative differences in HRQOL between groups. However, it is unlikely that any such differences would be dependent on level of lymphadenectomy. No power calculation was performed since the study population was defined beforehand. Limited statistical power, especially in the 5-year data, may have resulted in moderate or weak differences between groups remaining undetected.

Oesophageal cancer surgery is known to bring about long-lasting deterioration in HRQOL. ${ }^{13}$ The hypothesis that such deterioration is associated with more extensive lymphadenectomy was not confirmed in this study. The difference for transhiatal oesophagectomy and transthoracic oesophagectomy with more extensive lymphadenectomy have previously been evaluated in a randomised clinical trial ${ }^{27}$ and in observational research, ${ }^{25}$ where no differences in HRQOL beyond 3 months of surgery were observed. These results supported by findings in this study, may suggest that factors other than the extent of lymphadenectomy are involved in patients' trajectory of recovery. Comorbidity, more advanced tumour stages and proximal tumour location are other factors that seem to reduce HRQOL. ${ }^{16}$

More extensive lymphadenectomy introduces greater surgical trauma, but if extensive lymphadenectomy does not increase survival ${ }^{6} 7$ or decrease HRQOL, a discussion is needed regarding the preferred level of lymphadenectomy. A more tailored lymphadenectomy might be the optimal surgical procedure to reduce morbidity for these patients. ${ }^{28}$ However, since multidirectional spread is common in patients with oesophageal cancer, it may be difficult to identify and obtain sentinel nodes.

In conclusion, this population-based cohort study indicates that a more extensive lymphadenectomy during oesophageal cancer surgery does not decrease the shortterm or long-term HRQOL. There is a need for larger studies to establish the relation between extent of lymphadenectomy and long-term HRQOL.

Contributors All authors contributed with input in designing the study. Data collection and assembly of data was performed by $\mathrm{PL}$ and $\mathrm{JL}$. Data analysis was conducted by AJ. All authors contributed in interpreting the results, manuscript writing and approval of the final version of the manuscript.

Funding This work was supported by the Swedish Cancer Society (grant number 140323), the Stockholm Cancer Society (grant number 141223), and the Swedish Research Council (grant number 521-2012-2824).

Disclaimer The study sponsors had no role in the design of the study, data collection, analysis or interpretation of the results, the writing of the manuscript or the decision to submit the manuscript for publication.

Competing interests None declared.

Patient consent Obtained.

Ethics approval The Regional Ethical Review Board in Stockholm, Sweden.

Provenance and peer review Not commissioned; externally peer reviewed.

Data sharing statement No additional data are available.

Open Access This is an Open Access article distributed in accordance with the Creative Commons Attribution Non Commercial (CC BY-NC 4.0) license, which permits others to distribute, remix, adapt, build upon this work noncommercially, and license their derivative works on different terms, provided the original work is properly cited and the use is non-commercial. See: http:// creativecommons.org/licenses/by-nc/4.0/

\section{REFERENCES}

1. Parkin DM, Bray F, Ferlay J, et al. Global cancer statistics, 2002. CA Cancer J Clin 2005;55:74-108.

2. Enzinger PC, Mayer RJ. Esophageal cancer. N Engl J Med 2003;349:2241-52.

3. Lagergren J, Lagergren P. Oesophageal cancer. BMJ 2010;341:c6280

4. Allum WH, Blazeby JM, Griffin SM, et al. Guidelines for the management of oesophageal and gastric cancer. Gut 2011;60:1449-72.

5. Lagarde SM, Vrouenraets BC, Stassen LPS, et al. Evidence-based surgical treatment of esophageal cancer: overview of high-quality studies. Ann Thorac Surg 2010;89:1319-26.

6. Lagergren J, Mattsson F, Zylstra J, et al. Extent of lymphadenectomy and prognosis after esophageal cancer surgery. JAMA Surg 2016;151:32-9. 
7. van der Schaaf M, Johar A, Wijnhoven B, et al. Extent of lymph node removal during esophageal cancer surgery and survival. $J$ Natl Cancer Inst 2015;107:pii: djv043.

8. Viklund $\mathrm{P}$, Lindblad M, Lu M, et al. Risk factors for complications after esophageal cancer resection: a prospective population-based study in Sweden. Ann Surg 2006;243:204-11.

9. Daly JM, Fry WA, Little AG, et al. Esophageal cancer: results of an American College of Surgeons Patient Care Evaluation Study. J Am Coll Surg 2000;190:562-72. doi:discussion 72-3

10. Derogar M, Orsini N, Sadr-Azodi O, et al. Influence of major postoperative complications on health-related quality of life among long-term survivors of esophageal cancer surgery. J Clin Oncol 2012;30:1615-19.

11. Lagergren $\mathrm{P}$, Avery $\mathrm{KN}$, Hughes $\mathrm{R}$, et al. Health-related quality of life among patients cured by surgery for esophageal cancer. Cancer 2007;110:686-93

12. Donohoe CL, McGillycuddy E, Reynolds JV. Long-term health-related quality of life for disease-free esophageal cancer patients. World J Surg 2011;35:1853-60.

13. Jacobs M, Macefield RC, Elbers RG, et al. Meta-analysis shows clinically relevant and long-lasting deterioration in health-related quality of life after esophageal cancer surgery. Qual Life Res 2014;23:1155-76.

14. Scarpa M, Valente S, Alfieri R, et al. Systematic review of health-related quality of life after esophagectomy for esophageal cancer. World J Gastroenterol 2011;17:4660-74.

15. Doorakkers E, Konings P, Mattsson F, et al. Early Complications following oesophagectomy for cancer in relation to long-term healthcare utilisation: a prospective population-based cohort study. PLOS ONE 2015;10:e0121080.

16. Djarv T, Blazeby JM, Lagergren P. Predictors of postoperative quality of life after esophagectomy for cancer. J Clin Oncol 2009;27:1963-8.

17. Lagergren J, Bergstrom R, Lindgren A, et al. Symptomatic gastroesophageal reflux as a risk factor for esophageal adenocarcinoma. N Engl J Med 1999;340:825-31.
18. Aaronson NK, Ahmedzai S, Bergman B, et al. The European Organization for Research and Treatment of Cancer QLQ-C30: a quality-of-life instrument for use in international clinical trials in oncology. J Natl Cancer Inst 1993;85:365-76.

19. Blazeby JM, Conroy T, Hammerlid E, et al. Clinical and psychometric validation of an EORTC questionnaire module, the EORTC QLQ-OES18, to assess quality of life in patients with oesophageal cancer. Eur J Cancer 2003;39:1384-94.

20. Straatman J, Joosten PJ, Terwee CB, et al. Systematic review of patient-reported outcome measures in the surgical treatment of patients with esophageal cancer. Dis Esophagus. Published Online First: 15 Oct 2015. doi:10.1111/dote.12405

21. Fayers P, Aaronson N, Bjordal K, et al. The EORTC QLQ-C3O scoring manual. 3rd edn. Brussels, Belgium: European Organisation for Research and Treatment of Cancer, 2001.

22. King MT. The interpretation of scores from the EORTC quality of life questionnaire QLQ-C30. Qual Life Res 1996;5:555-67.

23. Osoba D, Rodrigues G, Myles J, et al. Interpreting the significance of changes in health-related quality-of-life scores. J Clin Oncol 1998;16:139-44.

24. Charlson ME, Pompei P, Ales KL, et al. A new method of classifying prognostic comorbidity in longitudinal studies: development and validation. J Chronic Dis 1987;40:373-83.

25. Rutegard M, Lagergren J, Rouvelas I, et al. Population-based study of surgical factors in relation to health-related quality of life after oesophageal cancer resection. Br J Surg 2008;95:592-601.

26. Brusselaers N, Mattsson F, Lagergren J. Hospital and surgeon volume in relation to long-term survival after oesophagectomy: systematic review and meta-analysis. Gut 2014:63:1393-400.

27. de Boer AG, van Lanschot JJ, van Sandick JW, et al. Quality of life after transhiatal compared with extended transthoracic resection for adenocarcinoma of the esophagus. J Clin Oncol 2004;22:4202-8.

28. Nagaraja V, Eslick GD, Cox MR Sentinel lymph node in oesophageal cancer-a systematic review and meta-analysis. J Gastrointest Oncol 2014;5:127-41. 